\title{
La participación ciudadana en una democracia por hacer
}

\section{Introducción}

Abrir espacios de participación a los sectores de la sociedad tradicionalmente excluidos, es una condición insoslayable en un contexto de pluralismo y apertura democrática. Más allá de discursos partidaristas que incorporen en su vocabulario el término "participación", es preciso favorecer iniciativas orientadas a crear esos espacios y a fortalecer los existentes. Si nos atenemos al espíritu de los acuerdos de paz firmados en enero de 1992, en Chapultepec, está claro que aún faltan condiciones para poder hablar de que existe democracia en el país. Este vacío, evidenciado por el ausentismo de sectores importantes de la sociedad salvadoreña, debe ser atendido por todo partido político o institución que considere con seriedad responder a las necesidades y derechos del ciudadano común.

El Salvador ha sido configurado históricamente por el autoritarismo y, en parte por lo mismo, por una tradición de fraudes electorales desde principios de siglo; lo que explica, en gran medida, la paulatina radicalización de las fuerzas sociales afectadas por esta situación. Sin entrar en la discusión sobre la forma en que estas fuerzas operaban y en sus intereses y necesidades específicas, es evidente que la hegemonía del orden militar instaurado por décadas en el país, imposibilitó todo intento - por moderado que fuese- por reivindicar los derechos civiles del ciudadano, configurando a la vez una psicología del autoritarismo.

Es a esa necesidad de participación en los asuntos de la comunidad y al derecho de inclusión que le asiste a todo ciudadano por su condición de tal, a lo que me referiré en este pequeño artículo, con el propósito de generar algunas reflexiones que contribuyan a la mejor comprensión y ejercicio del quehacer político por parte del ciudadano común.

La consulta de Opinión Pública de diciembre de 1998, llevada a cabo por el IUDOP de la UCA, proporciona datos muy significativos sobre la realidad polí- 
tica, económica y social del país durante ese año. Estos indicadores confirman la percepción de la mayoría de salvadoreños pobres: hay problemas que han empeorado, entre ellos el alto costo de la vida, la delincuencia y el desempleo. Si asumimos que todo partido político —antes de las elecciones- promete solucionar al menos parte de los problemas más urgentes del momento, y si los mismos siguen igual o empeoran durante la gestión pública de ese partido (y aún después), es evidente que la realidad contradice el habitual discurso de los políticos, lleno de promesas y falsas expectativas.

Si todavía alguien pregunta por qué el 70 por ciento de los entrevistados mostró escaso interés en votar en las elecciones del próximo marzo, tendrá que reflexionar sobre las razones que dan estos ciudadanos para adoptar esa actitud. En El Salvador de 1999, la vida de la gran mayoría de salvadoreños se ha deteriorado; las ilusiones que se tenían en víspera de la firma de los acuerdos de paz han desaparecido, y en su lugar los más pobres del país tienen como horizonte no sólo incertidumbre y descontento, sino más hambre y exclusión. Porque exclusión es carecer del poder individual suficiente para recibir compensación legal ante un atropello al derecho ciudadano; es recibir un recibo de cobro por un servicio, con el incremento arbitrario del 200 por ciento sobre el importe real del consumo, y carecer de las instancias a las que acudir para enmendar el abuso.

En un país donde la gran mayoría de ciudadanos es ignorado al momento de tomar decisiones que les desfavorecen (no así a los sectores privilegiados que las toman por ellos), resulta comprensible y justificable el aumento de desconfianza en los políticos, y la desmotivación generalizada por cumplir con el derecho ciudadano de votar.

Más allá de los números y estadísticas recopiladas, está claro que hay una correlación significativa entre el porcentaje de personas potencialmente excluidas del sufragio por decisión propia, y los índices de participación en zonas del país históricamente identificadas como poco desarrolladas. $\mathrm{Si}$, como se ha dicho anteriormente, los salvadoreños hemos vivido una historia de autoritarismo y fraudes electorales, y si el voto ha contribuido muy poco a cambiar la realidad en el país, resulta discutible el argumento de que las elecciones son un buen indicador de democracia. Es evidente que aun en el supuesto de que pudieran garantizarse elecciones libres en el país, cabría preguntarse qué porcentaje de personas en edad de emitir el sufragio siguen excluidas de este mecanismo y por qué.

Contando con información suficiente podríamos sustentar la hipótesis de que la mayoría de ciudadanos que se abstendrán de votar en marzo, urgen de espacios alternativos desde los cuales puedan expresarse y participar en iniciativas favorecedoras de sus intereses ciudadanos. Así, podríamos fundamentar con propiedad la tesis de que sólo ampliando y fortaleciendo estos espacios y consolidando los ya existentes podremos llegar a una democracia real. Por ejemplo, en 
un proyecto desarrollado el año pasado en San Francisco Gotera y patrocinado por la Fundación alemana Konrad Adenauer (ver Caminos-Torres, 1998), comprobamos que muchos jóvenes estudiantes de bachillerato del Instituto Nacional de esa ciudad, han identificado problemas que les afectan en su comunidad y/o institución educativa; sin embargo, confiesan no poseer la capacidad de solucionarlos, sobre todo porque sus sugerencias no son tomadas en cuenta por las autoridades competentes y, además, porque su comunidad no genera ninguna presión o iniciativa orientada a resolver el problema.

Asimismo, ante la necesidad de recreación apropiada en una comunidad rural con limitaciones, podría desarrollarse una política departamental descentralizada que favoreciera la creación de lugares sanos de diversión y esparcimiento, respetando las limitaciones del presupuesto asignado. Es decir, que un país subdesarrollado no puede de manera simplista justificar una política de marginación social, con el argumento de que no cuenta con suficientes fondos para ofrecer recreación a personas de escasos recursos.

Es importante, a fin de reformular criterios de apertura democrática, tomar en cuenta que la exclusión social no se reduce únicamente a la marginación económica; entenderlo así sería muy superficial. El fenómeno de la exclusión implica diferentes formas de ausentismo y de no-participación en los asuntos de interés comunitario. Si partimos del hecho que son muy pocas las instituciones civiles que representan los intereses y necesidades de importantes sectores de la sociedad, con mucha más razón se hace sentir el vacío y la frustración del ciudadano común por hacer valer su voz. Además, por el hecho de existir toda una jerarquía de necesidades, según la especificidad propia de cada grupo social, hay ciudadanos que asumen su condición de marginalidad a tal punto, que se vuelven disidentes dentro de su propia cultura, es decir, que discrepan de ciertos mecanismos convencionales que el sistema emplea para medir y legitimar niveles de participación.

Por tanto, el abstencionismo como no-participación en el ejercicio del sufragio, no puede entenderse únicamente como mera indiferencia o capricho de circunstancias, ni reducirse a la consecuencia de problemas de desplazamiento a votar, que si bien ocurren en el área rural, no abordan el fenómeno en su complejidad. Visto más de cerca, también el decir "no" es una forma legítima de afimarse ante la anacronía de los mecanismos institucionales que presuntamente siguen siendo válidos como indicadores de democracia.

\section{Juventud y democracia}

Cuando hablamos de participación hablamos de tolerancia y de un modo de convivencia. La participación del joven en beneficio de sus intereses ciudadanos es también un valor en sí mismo. Por lo tanto, es preciso darle especial atención al tipo de valores que deben emular los jóvenes, y esto sólo puede fortalecerse 
predicando con el ejemplo. Es evidente que los referentes personales e institucionales han perdido su significado, en un país donde predomina la intolerancia, la corrupción y el autoritarismo. Hay que actualizar la participación del joven adulto, y la de los mayores que no la ejercen - sin discriminación-, pero hay que preguntarse por qué la población joven del país acusa el mayor desinterés hacia los temas de tipo político. Esta apatía se debe, en gran parte, a una tradición largamente arraigada en el país, de identificar "la política" con "partido político" y al divorcio real existente entre la teoría de los políticos y su práctica. Las consecuencias de este divorcio son obvias: un circuito vicioso que comienza con muchas promesas y ninguna modificación en el estado de cosas, provocando frustración y pérdida de credibilidad en los sectores menos favorecidos de la sociedad.

Para comprender mejor el desencanto y la apatía que provoca el no poder cambiar ese orden de cosas, hay que tomar en cuenta las diferencias de hábitos, actitudes y percepciones entre cada generación. Esta brecha generacional coexistente produce diferentes actitudes y comportamientos con respecto a su realidad. Probablemente los muy jóvenes necesitan participar y aportar de alguna manera, pero no les convence el sufragio como altemativa, tal vez porque no ven en este mecanismo una forma de incidir sobre su realidad; mientras los mayores pueden creer en el voto, sin estar necesariamente de acuerdo con los candidatos del partido de su preferencia, o porque esperen cambios sustanciales de ellos.

Muchos salvadoreños que participaron en reinvindicaciones sociales durante el conflicto armado no sólo están desencantados, sino cansados y renuentes a participar en la solución de problemas de su comunidad, no necesariamente porque estén satisfechos con el estado de cosas imperante, sino porque además podrían perseguir objetivos distintos de los que buscaban cuando jóvenes; esto es psicológicamente comprensible, en la medida como este sector de la población pudo haber descuidado aspectos de formación y crecimiento personal, y, por lo mismo, identificado otras necesidades en su vida actual.

Indudablemente, las necesidades de cada generación difieren unas de otras; es por ello que el tipo de participación responde, en alguna medida, al tipo de necesidad. Sin embargo, al margen de las diferencias de edad y experiencias, hay factores que pueden ser comunes a varias generaciones, por ejemplo, la situación de extrema pobreza y lo que normalmente va aparejado a esta condición. Es en este sentido que las brechas generacionales en países con gran polarización social y desigualdad en la distribución del ingreso, no están del todo desvinculadas unas de otras en lo relativo a su sobrevivencia.

Toda iniciativa social que busque apropiarse de los espacios indispensables para hacer sentir la voz de quienes no la tienen, en la toma de decisiones, deberá partir de sus necesidades fundamentales, propiciando el diálogo con otros sectores. En El Salvador hace falta estimular la cultura del debate, más allá del reducido círculo de académicos o especialistas. 
Una de las formas de superar las actitudes patemalistas y asistencialistas que contribuyen a la no-participación de quienes se resisten a ser "representados" de esta forma, es creando las condiciones para un ejercicio saludable del cabildeo ciudadano, propiciando el diálogo y el debate con los funcionarios de gobiemo. Sólo en la medida como se propicie y estimule el debate constructivo entre los sectores normalmente excluidos, es como los futuros políticos de nuestro país asimilarán, como condición de todo proceso democratizante, la apertura a sus homólogos y a la ciudadanía en general.

La ausencia de una cultura del debate, como forma legítima de hacer sentir las opiniones propias y ajenas, se ha hecho sentir en el presente período preelectoral; los argumentos comúnmente esgrimidos, por parte de los políticos, para impugnar esta necesidad son muy pobres, y lo único que evidencian (y muchas personas así lo perciben) es su incapacidad por articular promesas realistas, es decir, factibles de ser puestas en práctica.

\section{Condiciones para la participación ciudadana}

Si en nuestro país continúa el deterioro y el descrédito de las instituciones representativas del cuerpo civil, y si aún no se desarrolla y fortalece la iniciativa ciudadana y la presión de la misma, no podremos hablar de participación democrática, ya que las decisiones sobre lo que debe hacerse en materia de "bienestar social" las seguirán tomando las élites, representantes de poderosos intereses económicos.

A continuación se enumeran algunas condiciones para estimular esta participación.

(a) Respeto y fortalecimiento de los derechos de los estudiantes en su ambiente de estudio. Se habla mucho de la pérdida de los valores tradicionales asociados a la democracia formal; sin embargo, es difícil invalidar la ausencia de referentes a emular por niños y adolescentes: los salvadoreños conocemos muy bien lo que la realidad cotidiana presenta día a día en El Salvador: agresividad, autoritarismo, robo, violación, asesinato, mendicidad, hacinamiento, etc. En un contexto social donde las relaciones de convivencia en tolerancia se han deteriorado, no podemos censurar con la moral tradicional la interiorización de estos "nuevos valores" por parte de los jóvenes. El hecho de que las pandillas posean la capacidad de aglutinar un grupo y subordinarlo a ciertas normas que sus integrantes estiman prioritarias y necesarias para su accionar, no es algo que podemos explicar afirmando simplemente que son modelos importados del pandillismo de Estados Unidos, o que es algo normal e inevitable en una ciudad con características tercermundistas.

La búsqueda del poder y los beneficios que éste conlleva es algo seductor para una pandilla, en una sociedad donde habitualmente se delinque, donde 
el poder se asocia con mucho dinero e influencias y donde proliferan los modelos transgresores de la ley, tanto en la vida cotidiana como en la televisión y el cihe.

Si es así como vivimos, es preciso que los adultos involucrados como educadores en el proceso de formación de los jóvenes estudiantes, posean ciertas características fundamentales de personalidad $-\mathrm{y}$ no únicamente títulosque les permita transmitir y fortalecer actitudes de cooperación y autoestima en los niños que recién comienzan a interiorizar pautas sociales de comportamiento. Estos educadores deberán poseer ética, ejercitar la solidaridad y la compasión, aspectos imprescindibles en el diario convivio con los estudiantes.

(j) Respeto y fortalecimiento de los derechos del niño en su ambiente familiar. Cuando tablamos de pérdida de valores tradicionales, necesariamente debemos observar cuidadosamente las relaciones interpersonales de la familia. Cuando en ésta impera el autoritarismo, la desigualdad de género, la violencia, el maltrato y la exclusión de sus miembros, en la discusión sobre lo que les concieme como grupo familiar, es evidente que se están negando los derechos fundamentales de sus integrantes.

La psicología demuestra convincentemente el daño mental y emocional que sufre el niño cuando es privado de las condiciones mínimas para su desarrollo como ser humano. Si este ejemplo individual se multiplica por el número de niños y adolescentes que viven en el país, está claro que estas carencias se vuelven, en términos de porcentaje, altamente significativas para comprender más objetivamente él por qué del deterioro psicológico, social y cultural de la mayoría de salvadoreños.

(c) Mayor difusión de resultados de investigaciones sobre los derechos del niño y el joven. Si la verdad libera es porque muestra lo que es como es, y no es de otra manera. Una mente joven y receptiva puede orientarse mejor si está debidamente informada de cómo son las cosas y por qué. Aquí hay mucho que hacer para los educadores y comunicadores que participan en el proceso educativo. Debemos observar e influir en las actitudes.

(d) Estimular la creatividad y el aporte de los jóvenes en el fortalecimiento de su propia participación, mediante el uso continuo de publicaciones sobre temas científicos y sociales, a ser usados en pequeños proyectos coordinados por los propios estudiantes.

El derecho a estar informado y a ser tomado en cuenta en las decisiones que afectan nuestros intereses, es algo prioritario en toda actividad orientada a fortalecer la participación ciudadana. Hablar de democracia es hablar de inclusión y participación, reconocer que quienes desdeñan los mecanismos comúnmente adscritos a la democracia formal, como son las elecciones, no 
siempre son las personas indiferentes a los problemas de su comunidad, sino que muchas veces carecen de los espacios necesarios para dar su aporte como ciudadanos. Aún no existe en el país la suficiente madurez cívica y política para gestar iniciativas públicas que identifiquen y alimenten las contribuciones y puntos de vista del ciudadano común, mucho antes de arribar al período electoral.

El inmediatismo y la improvisación también impide que se trabaje de forma más responsable y concentrada en la incorporación de sectores privados de voz y oportunidades en toda política de fortalecimiento de la sociedad civil. En este campo hay mucho trabajo para sociólogos, educadores, psicólogos sociales, antropólogos y políticos que se tomen con seriedad la tarea de comprender mejor la psicología del que vive en condiciones de marginalidad y exclusión.

Sería interesante identificar el sentido antropológico de la experiencia de vida de grupos que no está validada —es decir confirmada - por los referentes convencionales. Por ello es necesario identificar y posibilitar nuevos referentes, no solamente personas individuales sino, y sobre todo, actualizar la capacidad misma de grupos que aún no ejercen su derecho a expresarse, a fin de gestar su propio proyecto colectivo de vida, en alianza con otras asociaciones afines. Únicamente de esta forma comenzaremos a cimentar en la práctica los principios de una democracia participativa, que rejuvenezca o sustituya los mecanismos tradicionales.

\section{Derechos humanos, ciudadanía y participación}

Para comenzar a modificar las actitudes hacia la participación, es imprescindible reconocer los derechos fundamentales que nos asisten como personas y promover el ejercicio de los mismos. El artículo 12 de La Declaración Americana de Los Derechos y Deberes del Hombre (Bogotá-Colombia, 1948), afirma que "Toda persona tiene derecho a que se le reconozca en cualquier parte como sujeto de derechos y obligaciones, y a gozar de los derechos civiles fundamentales". El derecho a la expresión, fundamental en todo sistema democrático, está explícitamente reconocido en la Declaración Universal de Derechos Humanos -Art. 19- que dice textualmente: "Todo individuo tiene derecho a la libertad de opinión y expresión; este derecho incluye no ser molestado a causa de sus opiniones, el buscar, recibir, y difundir información e ideas por cualquier medio de comunicación y sin limitación de fronteras".

Es importante destacar que el marco jurídico de toda nación, respaldado por la constitución política, se encuentra en un contexto jurídico mayor; por lo mismo, al hablar de ciudadanía no significamos unilateralmente nacionalidad. Una de las limitaciones de la participación ciudadana es reducir sus dimensiones al concepto de nacionalidad; los derechos y obligaciones de cualquier ciudadano 
no se limitan únicamente a los ejercitados en un territorio y nación específica: hay derechos universales de los cuales participan todos los hombres y mujeres, sin distinciôh de raza, ideología y religión. Es decir que, formalmente hablando, los derechos civiles rebasan las fronteras de un país y de una nacionalidad.

Los especialistas en derecho internacional admiten dos categorías diferentes de derechos humanos: los derechos primarios y los secundarios. Los primarios son universales, inviolables y no pueden ser limitados: aquí se encuentran la libertad religiosa y el derecho a escoger un determinado régimen de gobierno. Los derechos secundarios no son absolutos y pueden ser reglamentados. En esta categoría están el derecho a la información, la libertad de expresión, la libertad de opinión y la libertad de reunión y asociación (Osorio Meléndez, 1997).

En El Salvador aún no existe una cultura que propicie y promueva el ejercicio diario de los derechos ciudadanos; si entendemos la apertura democrática en el país como proceso en transición, caracterizado por la gradual despolarización y desmilitarización, a partir de la firma de los acuerdos de paz, reconocemos que sin duda se ha divulgado más información sobre el tema de los derechos humanos y estimulado el discurso estatal que habla sobre el respeto hacia los mismos. Sin embargo, no es suficiente dar información, si no se propicia y cultiva en la práctica el respeto hacia estos derechos.

Hoy día sigue imperando el discurso a favor del medio ambiente y los derechos humanos, como si únicamente bastara hablar de ello para modificar la realidad. Mientras los ciudadanos no reconozcan el derecho que les asiste a participar creativamente, opinando, discutiendo, imaginando, descartando, incorporando, etc.; fortaleciéndose de las reflexiones personales sobre el aporte que pueden y deben dar en su comunidad, difícilmente saldremos del sometimiento y la pasividad, que se ha convertido en la rutina del salvadoreño que se lamenta que todo sigue igual o peor, pero que se conforma con repetir y consumir acríticamente lo que unos pocos le venden para su consumo diario.

\section{Referencias bibliográficas}

Ayala, Carlos, Comunicación Alternativa y Sociedod Civil, San Salvador: UCA editores, El Salvador, 1997.

Caminos-Torres, "Actitudes Democráticas Básicas en los Estudiantes de Bachillerato", (Mimeo), Proyecto de Investigación financiado por la Fundación Konrad Adenauer, 1998.

IUDOP-UCA, “Consulta de Opinión Pública", 1998.

Oller, M. Dolors, Ante una democracia "de baja intensidad" la democracia por construir, Barcelona: Cristianisme i justícia, 1994.

Osorio Meléndez, Hugo, Políticas de Información y Derecho, CIEDLA/Konrad Adenauer, 1997. 